\title{
Atualizações Contemporâneas do Corpociborgue
}

\section{Resumo:}

Este trabalho apresenta o resultado da dissertação de Mestrado intitulada Corpos Virtualizados, Danças Potencializadas: Atualizações Contemporâneas do Corpociborgue (2013), teve como principal objetivo propor o conceito de corpociborgue enquanto atualização do conceito de cyborg de Haraway (1985).

Palavras- Chave: Corpociborgue, Dança,

\author{
Isa Sara Rego ${ }^{1}$ \\ Ludmila Pimentel ${ }^{2}$
}

\begin{abstract}
:
This paper presents the results of the Master's thesis titled Virtualized Bodies, potentiated Dances: Updates the cyborgbody Contemporary (2013), aimed to propose the concept of corpociborgue while updating the concept of cyborg of Haraway (1985).
\end{abstract}

Keywords: post-human body, technoscience, cancer.

Ciborgue

1 Professora de Arte-Educação com ampla formação em Dança, Mestre em Dança, Universidade Federal da Bahia. E-mail: isasara5@hotmail.com (UFBA)

2 Professora Adjunto III na Escola de Dança da UFBA, Professora Permanente do Programa de Pós-graduaçao em Dança (PPGDAN-UFBA) e Professora Colaboradora do Programa de Pós-graduaçao em Artes Visuais (PPGAV-UFBA). E-mail: ludmilapimentel@hotmail.com 


\section{Introdução}

O que se propõe aqui é o estudo do conceito de cyborg proposto por Haraway (1985) para a proposição do conceito de corpociborgue na dança, enquanto resultado do processo de virtualização do corpo na dança (LÉVY, 2006). A virtualização do corpo é o resultado de um processo interativo (LEMOS, 2004), cibernético (WARNER, 1956) e líquido (BAUMAN, 2000) entre o que somos, aprendemos, transformamos e o que produzimos artisticamente. Do corpo virtualizado temos um hipercorpo (LÉVY, 1996), híbrido (PIMENTEL, 2008), que chamamos de corpociborgue.

Esse tema insere-se no debate absolutamente atual sobre corpo, dança e tecnologia. Sua relevância está implicada na nossa produção artística, enquanto artistas interessados na simbiose dança e tecnologia. Considerando ainda o desenvolvimento exponencial das novas tecnologias, este estudo lança as bases para processos artísticos que serão amplamente estudados, com a difusão das novas tecnologias.

Dentro dessa perspectiva, o presente estudo parte da hipótese que o processo de virtualização do corpo na dança é resultado de um movimento contemporâneo geral que caminha para o virtual, a condição contemporânea que habitamos apresenta um corpo reinventado (LÉVY, 1996), o qual chamamos de corpociborgue, pois:

a) Do cyborg de Haraway (1988) extraímos o corpo irônico, efervescente (BANNES, 1999), emancipado, decidido a romper com oposições entre natureza e cultura e interfaceado por tecnologias, que, de certa forma, estão no centro das questões ciborguianas, assim, a proposição do conceito corpociborgue está ligado à ideia de redes (LÉVY, 1999). Para Haraway (1988), essas redes estão dentro de nós, somos formados por uma coleção de redes, recebendo e fornecendo informações, em diálogo com outras redes que formam o nosso mundo.

b) Se o corpo virtualizado atualiza o modo de estar no mundo, o corpo virtualizado que dança, atualiza a produção de dança no mundo, fazendo imergir múltiplas categorias do corpociborgue na dança. No tocante ao corpo, o corpociborgue é o corpo que convive com as indisfarçáveis transformações da cibercultura, sendo afetado em todas as suas dimensões: do físico-fisiológico ao sensório, afetivo e mental. Tais categorias desenham o "estado da arte" da dança contemporânea. Pretende-se portanto propor o conceito de corpociborgue, com base nos estudos de cyborg, de Donna Haraway (1987); e apresentar cinco categorias do corpociborgue na dança, ilustrando teoricamente o tema a partir de obras artísticas selecionadas.

\section{O cyborg de Haraway (1986) atualizado em corpociborgue}

O híbrido corpo-máquina tem sua história no âmbito da discussão acadêmica e de pesquisa que remonta a meados do século XX, e dentro de ficção científica, imagens na literatura e do cinema, a partir da década de 1960. Nesse momento, nos voltaremos à genealogia da palavra cyborg, definiremos o conceito de cyborg de Haraway (1985) e apresentaremos o corpociborgue como uma atualização do conceito de cyborg de Haraway.

O que estamos propondo é que o cyborg de Haraway habita o corpociborgue. E através desse corpo atualizado e potencializado por meio das técnicas de aprimoramento físico, por implantes e próteses que pretendem corrigir funções avariadas do corpo, e também por conexões permitidas por serviços informáticos e telecomunicacionais ${ }^{1}$, que o corpociborgue está inserido na sociedade. 
Norbert Wiener ${ }^{2}$ (1894-1964) escreveu o livro Cybernetics, or control and communication in the animal and machine (1948), inaugurando a "cibernética" (1948), que é a premissa teórica que sustenta o sistema de funcionamento cyborg. A palavra cibernética deriva de um termo grego kubernetics ${ }^{4}$, que significa piloto: "a imagem do clássico piloto, com as mãos no timão no barco a velas, capta perfeitamente a essência da sua ideia" (KUNZRU, 2000, p. 124).

Segundo Hari Kunzru (2000), o conceito matemático da "Teoria da informação", de Claude Shannon, influenciou a ideia de "máquinas informacionais" de Wiener (1961), inaugurando a cibernética. Para Kunzru (2000), a informação é a principal característica que torna o ciborgue de hoje totalmente diferente dos ancestrais mecânicos, amplamente explorados na ficção literária e indústria cinematográfica. Para Haraway (2000), os cyborgs são máquinas de informação.

Wiener (1961) argumentou que os seres humanos, máquinas e animais têm sistemas semelhantes ao de um corpo cibernético homeostático ${ }^{5}$, com entradas e saídas (input-output) de feedback e loops $\mathrm{s}^{6}$ de controle e comunicação. A tese de Wierner (1950) diz que o funcionamento físico do corpo humano e de algumas máquinas de comunicação mais recentes são exatamente paralelas, no sentido analógico de dominar a entropia (desordem) através do feedback ou retroalimentação. A teoria das cibernéticas ${ }^{7}$ de Warner (1950) nos auxilia a compreender que a relação corpo e máquina, só se torna pertinente devido as trocas de informações incessantes estabelecidas durante a relação. Desde a introdução da energia elétrica no cotidiano do corpo humano, até o amplo entrelaçamento do corpo com o computador, a teoria cibernética caracteriza-se como agente motivador das transformações que ocorrem no mundo.

Para Lemos (2000), o ciborgue é o híbrido de cibernética e corpo, que só pode existir num mundo traduzido pela cibernética, em suas palavras, os "Cyborgs são seres simbióticos, misturas de carne e máquinas cibernéticas, que surgem de novos paradigmas: o eletrônico-digital e a biogenética" (2000, on-line).

Segundo Kunzru (2000), os seguidores de Wierner viram a cibernética como "uma ciência que explicaria o mundo como um conjunto de sistemas de feedback, permitindo o controle racional de corpos, máquinas, fábricas, comunidades e praticamente qualquer outra coisa" (KUNZRU apud SILVA, 2000, p. 55). Para Kunzru, "o sonho de Wierner, de uma ciência de comunicação e controle, apagou-se com o decorrer dos anos" (KUNZRU, 2000, p. 125), porém deixou dois importantes e máquina.

$2 \quad$ Um renomado matemático do Massachussets Institute.

3 Warner estudou o "piloto", ou peça mestra da máquina de vapor de James Watt (1736-1819), que regulava automaticamente a velocidade do engenho; e ele percebeu que para os computadores serem desenvolvidos, teriam que se assemelhar à habilidade dos seres humanos no controle de suas próprias atividades.

$4 \quad$ Referindo-se a mecanismos de direção ou controle.

5 Sistemas complexos precisam de homeostase para manter o equilíbrio e sobreviver. Homeostase é a propriedade de um sistema aberto de regular seu ambiente interno para manter uma condição estável.

6 Principais características dos sistemas cibernéticos são circuitos de retornos. Feedback é sinônimo de retroalimentação, são conceitos utilizados inicialmente pela cibernética e que após a publicação do livro de Norbert Warner, em 1948, foram integrados ou utilizados em outras ciências. A ideia de retroalimentação, de Warner, rompe com a casualidade linear e aponta para ideia de círculo causal, em que A age sobre B, que, em retorno, age sobre $A$.

7 A cibernética de Warner é dividida em Cibernética de primeira e segunda ordem. A Primeira Cibernética tem como principal objetivo viabilizar a comunicação entre humanos e máquinas, ou seja, por em comunicação sistemas de naturezas diferentes. A observação de estratégias que ressaltassem e realçassem a diferença no momento de adaptação do sistema ao seu meio colaborou com os processos de continuidade/transformação da própria cibernética, o que criou condições para que fosse formalizada uma nova teorização, ou seja, a Cibernética de Segunda Ordem. 
legados pioneiros para os estudos do corpo:

a) Descrever o mundo como uma coleção de redes;

b) Intuir previamente a não distinção entre corpos e máquinas.

Podemos concluir que tais legados são as principais premissas para propormos o conceito de corpociborgue nesse momento. Após Wierner (1948), houve um período histórico intensamente problematizado por questões políticas conflituosas. Nesse ínterim, surge o primeiro cyborg. Segundo Kunzru (2000), o primeiro cyborg do mundo foi um rato de laboratório, do programa experimental do Hospital estadual de Rockland, Nova York, no final dos anos 1950. Nada mais irônico. Se na contemporaneidade o corpo tende à virtualização (injeção, drogas, vacinas, inclusão de próteses etc.) é porque no passado, não distante, tais tendências foram rigorosamente testadas em cobaias ou ratos de laboratório.

Manfred Clynes ${ }^{8}$ e Nathan Kline ${ }^{9}$ (1960) usaram pioneiramente a expressão cyborg num artigo $^{10}$ escrito para a revista Astronauta, intitulado Cyborgs and Space, cujo rato de Rockland é um dos astros da narrativa. $O$ termo cyborg é a abreviatura de cybernetic organism, ${ }^{11}$, expressão cunhada para descrever o conceito do corpo ampliado, "um homem melhor adaptado aos rigores da viagem espacial" (KUNZRU, 2000, p.39).

Clynes e Kline (1995) imaginaram um astronauta possuidor de um coração controlado por anfetaminas einjeções e pulmões substituídos porcélulas energéticas inversas, alimentadas por energia nuclear. Em síntese, o artigo tratou das vantagens e desvantagens da autorregulação do sistema corpo-máquina no espaço exterior (outer space). Para esses autores, o cyborg é uma construção orgânica artificial simbiótica, capaz de funcionar de forma autônoma e suportar a gravidade de ambientes externos.

No livro Manifesto Ciborgue: ciência, tecnologia e socialismo-feminista para o século XX ${ }^{12}$ (1985, 2000) Donna Haraway ${ }^{13}$ utiliza a imagem do cyborg para problematizar as relações entre corpo, tecnologias, sociedade e cultura. Ao afirmar que "um cyborg é um organismo cibernético,

$8 \quad$ Nasceu em 1925, foi um cientista e especialista em computadores.

$9 \quad$ Nasceu e morreu entre 1916-1983, foi um renomado psicólogo.

10 CLYNES, Manfred; KLINE, Nathan. Cyborgs and Space. Revista Astronauta, 1960. Disponível em: <http:// web.mit.edu/digitalapollo/Documents/Chapter1/cyborgs.pdf $\geq$. Acesso em: 01 out. 2012.

11 Organismo Cibernético, Tradução nossa.

12 HARAWAY, Donna. Manifesto ciborgue: ciência, tecnologia e feminismo socialista no final do século XX. In: SILVA, Tomaz (Org.). Antropologia do ciborgue: as vertigens do pós-humano. Belo Horizonte: Autêntica, $p$. 36, 2000.

13 Bióloga, formada em zoologia e filosofia, professora da Universidade da Califórnia, nos Estados Unidos, autora de diversos livros, vem se destacando enquanto feminista, neo-marxista e pós-modernista. Em função dos seus estudos, lecionou sobre os Estudos da Mulher e História da Ciência, na Universidade do Havaí e na Universidade Johns Hopkins. Nessa mesma época, em setembro de 2000, recebeu a maior honraria concedida pela Sociedade de Estudos Sociais da Ciência: O prêmio JD Bernal Award. 
um híbrido de máquina e organismo, uma criatura de realidade social e também de ficção" (HARAWAY, 2000, p. 36), Haraway sintetiza a proeminência do corpo diante do amplo entrelaçamento dos corpos humanos com as tecnologias, e o debate que essa simbiose vem provocando no pensamento atual.

Esse livro ${ }^{14}$, por ser uma literatura que oferece um grande espectro de análise das relações entre o feminismo e as novas tecnologias, é aqui discutido por ser também uma primeira abordagem sobre o binômio corpo e tecnologia, arcabouço teórico da proposição do conceito corpociborgue.

O cyborg de Haraway traz no conceito a construção de um discurso crítico sobre os poderes hegemônicos, materializando novos significados para a natureza, corpo humano e as relações de diferença. Além disso, o conceito lança luz sobre a visão de Haraway para uma ciência emancipatória. Haraway (1985) reconhece que o cyborg é derivado de tecnologias desenvolvidas em meados do século XX, incluindo as tecnologias de comunicações e tecnologias médicas, como pesquisa de próteses e da biotecnologia. Ela argumenta que ser ou tornar-se um cyborg é uma questão de sobrevivência e deseja que as mulheres, em particular, sejam estas sobreviventes.

A escrita desse manifesto de Haraway foi um marco nos anos 1980, por ser um período de profundas modificações socioculturais, que Santaella $(2003,2004,2007,2010)$ denomina de "cultura das mídias". O ser humano, inserido nessa cultura, é naturalmente corpociborgue. Isso porque compreendemos que os corpos humanos são "naturalmente construídos, tal como um ciborgue" (HARAWAY, 2009, p. 24).

Para Haraway, as tecnologias do corpo que produzem o sujeito moderno estão se tornando mais fragéis e estão sendo gradualmente substituídas por tecnologias de uma ordem inteiramente diferente. Os limites que proporcionavam configurações de poder e hierarquia estão a dissolver-se. Em seu lugar estão surgindo novos tipos de limites, fluidos e imprecisos, que rompem com os dualismos modernos.

De uma certa perspectiva, um mundo do ciborgue significa a imposição final de uma grade de controle sobre o planeta. [...] De outra perspectiva, um mundo dos ciborgues pode significar realidades sociais e corporais vividas, nas quais as pessoas não temem sua estreita afinidade com animais e máquinas, que não temam identidades permanentemente parciais e posições contraditórias (HARAWAY et al., 2009, p. 46).

14 O Manifesto Ciborgue (1985) de Haraway é um autentico cruzamento de caminhos. Nela convergem diferentes disciplinas acadêmicas (biologia, antropologia, história, artes etc.), diversas tecnologias (fotografia, manipulação genética, agricultura etc.) e um discurso construído a partir das suas experiências e viagens, seus ensaios são simultaneamente história da ciência, análise cultural, investigação feminina e postura política. 
Nessa perspectiva, surgem novos "limites", que procuram a infraestrutura necessária para as configurações emergentes de saber/poder e de novos "sujeitos" pós-modernos. No momento em que as novas tecnologias começam a atuar sobre e fazer parte dos corpos das pessoas, novos tipos de subjetividades serão gerados, por assim dizer, organismos cibernéticos: corpociborgues. Haraway (2009), com a seguinte frase, inaugura um dos mais famosos pensamentos, cujas relações corpo e tecnologia são destacadas: “Um ciborgue é um organismo cibernético, um híbrido de máquina e organismo, uma criatura de realidade social e também de ficção" (p. 36).

Haraway (2009) denomina seu ensaio como um argumento em favor do prazer da confusão de fronteiras, das quais três são destacadas: a fronteira entre humano e animal, a fronteira entre o animal-humano (organismo), de um lado, e a máquina do outro, e a fronteira entre o físico e o não físico: “Assim, meu mito do ciborgue significa fronteiras transgredidas, potentes fusões e perigosas possibilidades" (p. 45).

Para Haraway (2009), a cultura high tech contesta esses dualismo. Seus estudos são intrigantes, pois, na relação corpo-máquina, nunca está claro o papel do agente e do receptor na relação: “Não está claro o que é mente e o que é corpo em máquinas que funcionam de acordo com práticas de codificação" (p. 91). No coração do cyborg de Haraway encontra-se uma profunda discussão sobre as transformações nos campos sociais que constituem a nossa realidade. A revolução que aponta a autora não implica apenas uma reconfiguração de elementos que permaneceram ao longo do tempo. Ela envolve uma mudança na qualidade e até mesmo na substância desses elementos.

Artefatos, objetos ou até mesmo convenções culturais, como a língua e os rituais religiosos, acumulam modificações ocasionadas por diferentes indivíduos no transcurso do tempo. Assim explica o psicólogo Michael Tomasello (1999), ao dizer que "os seres humanos costumam dispor de capacidades de aprendizagem sociocognitiva e cultural para criar, enquanto espécie, produtos cognitivos únicos baseados na evolução cultural cumulativa" (p. 54).

E esses processos de aprendizagem cultural são particularmente poderosos porque se baseiam na adaptação cognitiva exclusivamente humana para compreender os outros como seres intencionais iguais a si mesmos, que criam formas de aprendizagem social que agem como uma catraca, preservando fielmente estratégias recém-inovadoras no grupo social até que haja outra inovação para substituí-las (p. 55).

A mudança nos meios comunicacionais implica um processo cumulativo em que pode haver a substituição de suportes antigos por novos e que tem como resultado o fato de a cultura relacionada aos meios mais recentes prevalecer. Não é necessário que o humano porte implantes, chips, submeta-se a transplantes para que seja chamado de cyborg. O ser humano é naturalmente cyborg, pois incorpora desde sempre ferramentas que ampliam suas capacidades corporais. E se torna um corpociborgue ao incorporar os processos de virtualização do corpo (LÉVY, 1996), característicos da sociedade contemporânea.

Santaella (2004) nos chama atenção para o fato de que as tecnologias atuais implicam não apenas reconstituições da vida social e cultural, mas também mudanças do corpo humano. Sob essa perspectiva, chamamos de corpociborgue o novo conceito do corpo humano em resposta aos sistemas de extensões tecnológicas que emanam na fluidez contemporânea e de sua recorrente exploração pelos artistas interessados na pesquisa dança e novas tecnologias. 
Devemos compreender o corpociborgue como um organismo complexo, cuja dinâmica está atrelada às novas tecnologias da cibercultura. A tecnocultura vem transformando corpos, assim como esses têm modificado ferramentas e artefatos da tecnologia digital. Segundo Santana (2006), o corpo não precisa ser oco para comportar as tecnologias que surgem, pois ele já é aberto o suficiente para ganhar alterações físicas e neuronais, na verdade, é a máquina que fica mais orgânica para realizar a simbiose com o homem.

Compreendemos que o processo de ciborguinização efetivou-se ao longo desse processo revolucionário, que foi possível graças à combinação de diversos fatores, dentre eles, a substituição do corpo, por máquinas. Com inúmeras vantagens a frente do corpo, máquinas começaram a penetrar no cotidiano dos corpos, a partir da substituição da força muscular do corpo (SANTAELLA, 2010). Inicialmente movidas a vapor e posteriormente por eletricidade, as máquinas impetraram a era aos grandes empresários, aumentando a produtividade, reduzindo impostos e ampliando a capacidade do corpo em "força muscular". A força de um único sujeito é ampliada a mais de cem trabalhadores reunidos: capacidades ampliadas, custos reduzidos. Por isso denominada, máquinas musculares, essa categoria herdou o árduo e grosseiro trabalho operário de "repetir e repetir". A reprodução mecânica de gestos humanos introduziu um considerável ganho em eficiência, uma vez que a aceleração dos movimentos que elas permitem, traduz-se imediatamente, num maior rendimento em realização das tarefas.

O corpociborgue, como híbrido do corpo e máquina, habita a cibercultura e a mais recente cultura da mobilidade (SANTAELLA, 2007). É com o surgimento da sociedade de informação, que o corpociborgue pode sair da ficção-científica e ingressar na vida cotidiana, e consequentemente na arte. Aqui nos interessa observá-lo e propô-lo nos territórios da dança.

O corpociborgue é o corpo do cotidiano que habita o espaço da experiência humana (SANTAELLA, 2007). Essa experiência transformada pelas novas tecnologias reconstrói o cotidiano do corpociborgue.

\section{A proposição do conceito de Corpociborgue}

Atualmente, assistimos a numerosas tentativas de mudar o corpo, de personalizá-lo, de virtualizá-lo: “Implantes. Transplantes. Enxertos. Próteses. Seres portadores de órgãos artificiais. Seres geneticamente modificáveis. Sentidos farmacologicamente intensificados: a percepção, a imaginação e a atenção" (TADEU, 2000, p. 12). Complexidades que abarcam desde o fisiculturismo, as cirurgias plásticas, a artes corporais até os limites das formas mais radicais de modificações corporais.

Os estudos do corpo tecnologizado trazem em seu bojo uma série de conceitos que ocupam regiões semânticas próximas ao conceito de corpociborgue. No mundo científico, midiático e 
artístico esse tema tem aparecido, atualmente, associado à chamada cultura do "pós-humano ${ }^{15}$ ". Para Santaella, a expressão pós-humano é "um meio de expressão encontrado para sinalizar as mudanças físicas e psíquicas, mentais, perceptivas, cognitivas e sensórias que estão em processo" (2007, p. 67).

Santaella (2003) diz que o corpo está sob interrogação. Assim como a expressão "pós-humano", outras nomenclaturas foram surgindo em publicações de arte e culturas cibernéticas para dar conta da emergente virtualização do corpo na contemporaneidade. Nossa proposta é apresentar esses conceitos, promovendo entre eles uma atualização. Atualizar esses conceitos, em corpociborgue, sintetiza a ideia principal do que é o corpo, ao mesmo tempo real e virtual; o virtual aparece como um prolongamento "e o corpo é basicamente uma imagem que aparece dotada de materialidade, em concorrência com a materialidade do corpo físico" (ORTEGA, 2008, p. 13). Vejamos a seguir a revisão de alguns conceitos, que foram sendo introduzidos por teóricos contemporâneos, com a finalidade de caracterizar a mutação dos corpos, como fruto das simbioses do corpo com as máquinas:

a) 1998 - O corpo Biocibernético de Lúcia Santaella. O adjetivo "biocibernético" vem sendo utilizado desde 1997, como afirma a autora em Corpo e comunicação: os sentidos do pós-humano (SANTAELLA, 2004, p. 56). O corpo biocibernético é usado, em Santaella (2004), dando a ideia de corpo "protético" e de "ciborgue" (p. 54). Já em Linguagens líquidas na era da mobilidade (2007), Santaella diz que o sentido da palavra biocibernético é similar a ciborgue, mas prefere o uso do prefixo "bio", porque biocibernético expõe a hibridização do biológico e do cibernético e de maneira mais explícita.

b) 1996 - O corpo paradoxal de José Gil. Para Gil (1999), o corpo configura-se no espaço. E esse espaço ocupado pelos entornos do corpo e também pelos suportes ou dispositivos que, incorporados ao corpo, são as próteses naturais do corpo. Em Gil (1999) o corpo é um metafenômeno, “visível e virtual ao mesmo tempo, feixe de forças e transformador de espaço e de tempo, emissor de signos e transsemióticos" (GIL, 2009, p. 56).

c) 1997 - O conceito de mente estendida, de Andy Clark. Trata-se de uma corrente bastante atual da filosofia da mente apresentada por Clark como a característica do corpo que o torna "naturalmente ciborgue". Segundo Molina (2007), Clark compreende a mente naturalmente estendida até os limites do corpo, englobando também o mundo.

d) 2000 - O ciborgue, de André Lemos. Em Lemos "o Devir da humanidade é um devir cyborg. O primeiro homem, que de uma pedra faz uma arma e um instrumento, é o mais antigo ancestral dos cyborgs" (LEMOS, 2008, p. 165). Em sua compreensão, o cyborg sempre existiu, mas é na sociedade contemporânea que a condição cyborg encontra seu ponto de referência mais digno

15 Segundo Santaella (2007), o efeito imediato que a expressão provoca no leitor é inquietante, e nós acrescentaríamos repulsivo. Via de regra, o prefixo "pós" nos leva ao entendimento que "o humano" já se foi. Abre-se um campo de debate entre os teóricos que defendem o uso da expressão versus os teóricos que reprimem o seu uso. Embora Santaella $(2003,2004,2007)$ seja um dos principais arcabouços teóricos dessa dissertação, ainda estamos nos questionando acerca da expressão "pós-humano", que é arbitrariamente abraçada pela autora. Sem dúvida, o uso da expressão "pós-humano" nos artigos de Santaella é, no mínimo, inquietante para nós, a expressão tem sido usada na função intensificadora de questões. Se para Santaella (2007) a condição pós-humana "diz respeito à natureza da virtualidade, à genética, à vida, à inorgânica, aos ciborgues, à inteligência distribuída, incorporando biologia, engenharia e sistemas de telecomunicação" (SANTAELLA, 2007, p. 38), compreendemos que a proposição corpociborgue leva no bojo essa compreensão, incorporando a humanidade a ela. 
de manifestação. Seus estudos são interligados com Pierre Lévy (1996) e, dessa parceria, surge o "corpo hipertexto": A partir da virtualização da cultura contemporânea, emerge o "corpo hipertexto" como superfície de escrita, marcado por excessos. Segundo Lemos, “o corpo pósmoderno é uma superfície de escritas de vários textos" (2002, p. 167).

Parece claro, a partir desses conceitos apresentados, que em curto período de tempo surgiram várias expressões que dizem da virtualização do corpo na contemporaneidade (LÉVY, 1996). Concordamos com Bruno (1999 apud SANTAELLA, 2004, p. 29), que as novas tecnologias transformaram as fronteiras do corpo. Hoje, as técnicas adentram o corpo não apenas para reparar funções avariadas, mas também para ampliá-las, estimulá-las, transformá-las, ou mesmo criar novas funções.

Para finalizamos a lista dos conceitos que pretendem dar conta do cyborg, acrescentamos o conceito de "corpo sem órgão", de Deleuze (Deleuze; Guattari, 1988) por ser uma premissa teórica para os estudos do corpo, inclusive fonte para alguns dos autores acima, como Pierre Lévy (1996), José Gil (1999) e André Lemos (2000).

Para Machado (2003), o corpo sem órgãos deve ser definido, não propriamente como um corpo ausente de órgãos, mas pela existência de órgãos indeterminados, que só temporariamente se tornam órgãos determinados. Nesse sentido, o corpo sem órgãos é o aspecto ou a dimensão virtual do corpo.

Quando Deleuze e Guatarri (1988) utilizam o termo mecânico e máquinas, a intenção é subverter o sentido adquirido com as teses mecanicistas, de que as máquinas de que o corpo apoia-se em rigorosos princípios de leis causais, o objetivo é elaborar uma maquinaria que não só represente o funcionamento do corpo e da natureza, mas também que o produz intensamente. Sob essa perspectiva compreendemos que a máquina jamais será a metáfora da realidade, mas é a própria realidade em produção indiscriminada (SANCHEZ, 2008).

A nossa contemporaneidade nos apresenta uma pluralidade de "líquidos" (BAUMAN, 2000). Nesse cenário, surge o corpociborgue, atualizando as múltiplas tendências conceituais. O resultado é pensar o corpo como um agente da experiência humana, virtualizado, inserido na cibercultura, “a atualização é criação, invenção de uma forma a partir de uma configuração dinâmica de forças e finalidades" (LÉVY, 1996, p. 16). O atual é, então, uma produção de qualidades novas que responde ao virtual, enquanto este é um potencial que redefine constantemente a atualidade.

Para Lemos, existem dois tipos de ciborgues: o ciborgue protético e o ciborgue interpretativo. O primeiro simboliza a simbiose entre o orgânico e o inorgânico. Já “o cyborg interpretativo se constitui pela influência dos mass media, coagido que é pelo poder da televisão ou do cinema. Assim, a cultura de massa e do espetáculo nos fez cyborgs interpretativos" (LEMOS, 2004, p. 172).

Se o corpociborgue é o resultado do processo simbiótico entre o corpo, a técnica e a cultura, o ciborgue de Lemos (protético e interpretativo) é o resultado da virtualização do corpo na contemporaneidade, que reformula e redimensiona a nossa maneira de ser e estar no mundo. Tal é o cenário onde o corpociborgue vive plenamente, como criatura da realidade social e também de ficção: híbridos, extensões e corpo, quimeras, mosaicos. A composição singular do sujeito que encarna o futuro aberto das ambiguidades e diferenças. Agora, em um mesmo corpo, reúnem-se o orgânico e o mecânico, a natureza e a cultura, o original e o simulacro, a realidade social e a ficção científica. Em outras palavras, como escreve Haraway (1985, p. 254): “somos todos ciborgues. O ciborgue é nossa ontologia, nos outorga nossa política". 
Nas palavras de Lemos, "o processo de cyborgização contemporâneo nada mais é que a continuação inelutável dessa ordem à parte formada pelo homem, de sua saída da natureza na construção de uma segunda ordem artificial" (LEMOS, 2004, p. 165). O ciborgue simboliza todo processo da virtualização do corpo, com o advento das tecnologias do virtual.

Esta dissolução das fronteiras pós-humano é incorporada conceitual, figurativa e metaforicamente na figura do ciborgue, que fala para a inseparabilidade do corpo e da máquina e como uma representação visual desta união contraditória (HARAWAY, 1991). O ciborgue não só exemplifica a era pós-humana (CLARKE, 2002; ORLAN, 1996), é também uma representação manifesta de que a tecnologia é um aspecto integral da identidade humana (CLARK, 2003; ZYLINSKA, 2002a).

A partir da inserção do virtual no cotidiano, Deleuze anuncia (1992) o declínio das instituições disciplinares e de confinamentos estudados em Foucault. De uma ordem inteiramente diferente, enquanto as técnicas disciplinares operavam um circuito fechado, os novos dispositivos apoiam-se na tecnologia para produzir formas ágeis e instantâneas de controles incessantemente livres ao ar.

Pensar o corpociborgue atualizado é pensar o corpo nutrido por tecnologias que virtualizam o corpo (LÉVY, 1996). A originalidade das mutações em curso está na linha de continuidade e do aumento de complexidade do que chamamos de corpociborgue.

Escrever sobre a dança propõe o estudo cultural do corpo, pois a dança se dá no corpo ${ }^{16}$, e ainda que o corpo não se faça presente na cena da dança, é através do corpo que a concepção da obra é criada e posta em cena. Falamos, assim, do corpo múltiplo e mutante, aberto aos acontecimentos, habitado por uma infinidade de corpos, habitado pelo ciborgue e uma infinidade de ideias, que não pode ser reduzido a uma identidade, pois a multiplicidade é a sua própria constituição.

O ciborgue habita o corpo, assim como a dança se dá no corpo, compreendemos que o ciborgue e a dança se encontram no mesmo substrato, ou seja, ambos buscam a existência a partir do corpo. Por assim dizer, pretendemos com esse estudo apresentar de forma pioneira os corposciborgues na dança, e por isso, esse estudo torna-se um terro fértil, para propor questões emergentes, cuja dinâmica corpo, cultura, dança e técnica, estejam atreladas.

A história da arte demonstra que o corpo humano sempre esteve no foco da atenção dos artistas. A crescente centralidade do corpo nas artes, a partir das vanguardas artísticas do século passado, tratou de problematizar o corpo, promovendo angústia, tensão e questionamentos (SANTAELLA, 2004). Longe de estar à margem dessas questões, o corpo que dança tem se tornado foco de contestações, fazendo emergir complexidades até então insuspeitadas.

Sob uma multiplicidade de aspectos e dimensões que colocam em evidência a virtualização do corpo na artes, temos perseguido a hipótese de que a crescente simbiose do corpo que dança com as novas tecnologias (interativas, ou não) indica o surgimento de diferentes categorias de virtualização do corpo na dança.

A fusão corpo-dança-tecnologia manifestou-se independentemente do uso de aparatos tecnológicos digitais. Conforme os conceitos aqui explicitados, o corpo tende à virtualização (LÉVY, 1996). O que estamos argumentando é a potencialização da capacidade expressiva do corpo na dança, que se faz acompanhar pela transformação mútua do corpo com o mundo tecnologizado. Isso nos faz pensar que a sapatilha de ponta, criada por Filipo Taglioni, e os mecanismos de suspensão utilizados em Les Sylphides, as "máquinas de voar, primeiramente introduzidos pelo coreógrafo Charles Didelot 16 Sem o corpo a dança não pode existir. 
nos balés românticos no final do século XVIII, exemplificam o uso de aparatos não digitais, que, com suas próprias regras, condicionam o corpo até os limites das suas potencialidades (SANTANA, 2006).

Queremos dizer que essas tecnologias também interferem na configuração do corpo, entretanto compreendemos que o ciborgue na dança surge da condição política de transgressão, emancipação da representação, interdisciplinaridade, em simbiose com a tecnologia. O conceito de tecnologia é empregado para se referir não somente à dimensão dos aparatos, mas para se embutir às questões fenomenológicas dos feitos humanos veiculados por uma técnica específica (PINTO, 2005). $\mathrm{O}$ artista começa a utilizar a tecnologia no seu processo criativo, transferindo a sua função técnica para a função estética. Nesse sentido, a ciborguinização é reconhecida como tendência constante na história recente da dança, enquanto dinâmicas de ruptura e ironia, que se formaliza em virtualizações do corpo.

\section{Referências}

BANES, Sally. Greenwich Village 1963: avant-garde, performance e o corpo efervescente. Rio de Janeiro: Rocco, 1999.

BAUMAN, Zigmund. Modernidade líquida. Rio de Janeiro: Jorge Zahar, 2001.

CLYNES, Manfred; KLINE, Nathan. Cyborgs and Space. Revista Astronauta, 1960. Disponível em: <http://web.mit.edu/digitalapollo/Documents/Chapter1/cyborgs.pdf $\geq$. Acesso em: 01 out. 2012.

DELEUZE, G., GUATTARI, F. Différence et répétition $\square$. Trad. br. de Luis Orlandi e Roberto Machado. Rio de Janeiro: Graal, 1988.

Mil platôs, capitalismo e esquizofrenia. Rio de Janeiro: editora 34, vol. 3 e vol. 5, 1999.

DOMINGUES, Diana. A arte no século XXI: a humanização das tecnologias. São Paulo: Unesp, 1997.

GIL, José. Movimento total: o corpo e a dança. São Paulo: Iluminuras, 2009.

GLUSBERG, Jorge. A arte da performance. São Paulo: Editora Perspectiva, 1987. GOLDBERG, Roselee. Performance art. Madrid: Destino, 1979.

HARAWAY, Donna. "A Cyborgue Manifesto: Science, Technology and Socialist-Feminist in the late twentieth century". En: Simians, cyborgs and women: the reinvention of nature. New York: Routledge, 1991.

. Antropologia do ciborgue. 2009.

. Manifesto ciborgue: ciência, tecnologia e feminismo socialista no final do século 20. Disponível em: <http:/ / pt.scribd.com/doc/55060755/Haraway-Donna-Ciencia-Cyborgs-yMujeres>. Acesso em: Jan. 2012.

HARAWAY, Donna; KUNZRU, Hari; TADEU, Tomaz. Antropologia do ciborgue: as vertigens do pós-humano. 2. ed. Belo Horizonte: Autêntica, 2009.

KUNZRU, Hari. Genealogia do ciborgue. In: SILVA, Tadeu Tomaz da (Org. e trad.). Antropologia do ciborgue. Belo Horizonte: Autêntica, 2000. 
. "Você é um ciborgue": um encontro com Donna Haraway. In: SILVA, Tomaz Tadeu da

(Org.). Antropologia do ciborgue: as vertigens do pós-humano. Belo Horizonte: Autêntica, 2000. p. 19-36.

LEMOS, André. Ciberarte. Disponível em:

<http://www.facom.ufba.br/ciberpesquisa/lemos/CIBERARTE.pdf>. Acesso em: 20 jan. 2012.

. Cibercultura: tecnologia e vida social na cultura contemporânea. Porto Alegre: Sulina, 2008.

Cidade-ciborgue: A cidade na cibercultura. Disponível em: <http://www.facom.ufba.br/ ciberpesquisa/andrelemos/cidadeciborgue.pdf >. Acesso em: 01 out. 2012.

Cidade-ciborgue. In: Galaxia. Revista Transdisciplinar de Comunicação, Semiótica, Cultura. n. 8. PUC-SP, São Paulo, EDUC: Brasília, 2004.

Disponível em: <http://www.facom.ufba.br/ciberpesquisa/andrelemos/cidadeciborgue.pdf>. Acesso em: 10 jan. 2012.

LÉVY, Pierre. Cibercultura. Trad. Carlos Irineu da Costa. São Paulo: Editora 34, 1999.

. O que é o virtual. São Paulo: Editora 34, 1996.

PIMENTEL, Ludmila. Corpos e bits: linhas de hibridação entre dança e novas tecnologias.

Dissertação (Mestrado em Comunicação e Cultura contemporâneas) - Universidade Federal da Bahia. Disponível em: $<$ http://www.facom.ufba.br/ciberpesquisa/downloads/dis ludmila.pdf>. Acesso em: 20 Jan. 2012.

. El cuerpo híbrido en la danza: transformaciones en el lenguaje coreográfico a partir de las tecnologías digitales. Análisis teórico y propuestas experimentales. (Tesis doctoral). Valencia: Universidade Politécnica de Valencia, 2008.

. La coreografía digital interactiva. ARTECH 2010 "Envisioning Digital Spaces”, Guimarães, Portugal School of Architecture, University of Minho: 22 e 23 april, 2010, p.140-149.

SANTAELLA, Lucia. Corpo e comunicação: sintomas da cultura. São Paulo: Paulus, 2004. 2003.

Culturas e artes do pós-humano: da cultura das mídias à cibercultura. São Paulo: Paulus, . Linguagens líquidas na era da mobilidade. São Paulo: Paulus, 2007.

. “O homem e as máquinas”. In: DOMINGUES, D. (Org.). A arte no século XXI: a humanização das tecnologias. São Paulo: Editora Unesp, 1997.

TOMASELLO, Michael. Origens culturais da aquisição do conhecimento. São Paulo: Martins Fontes, 1999. 